\title{
"Comparative study between trochanteric fixation nailing and cemented bipolar hemiarthroplasty for the treatment of unstable osteoporotic intertrochanteric neck femur fractures in elderly patients."
}

\author{
Dr Ulhas V Sonar, Dr Milind V Ingle, Dr Maruti R Koichade, Dr Avinash B \\ Yelne, Dr Naveen Malu \\ (Indira Gandhi Government Medical College, Nagpur, Maharashtra; India.)
}

\begin{abstract}
Objective: To compare the results of trochanteric fixation nailing (TFN) and cemented bipolar hemiarthroplasty in unstable osteoporotic intertrochanteric neck femur fractures in elderly patients.

Method: Thirty patients, 65 years or older with unstable osteoporotic intertrochanteric neck femur fractures were treated with either trochanteric fixation nailing or cemented bipolar hemiarthroplasty. Results were evaluated by Harris Hip Score.

Results: Average age of patients for TFN and hemiarthroplasty was $75.73 \pm 6.57$ years and $78.07 \pm 6.16$ years respectively. Average trauma surgery interval for TFN and hemiarthroplasty was 5.7 days and 6.56 days respectively. Average surgery time for TFN and hemiarthroplasty was 74.33 minutes and 86.33 minutes respectively. Average stay in the hospital for TFN and hemiarthroplasty group was 18.23 days and 18.77 days respectively. In TFN group fourteen fractures were A2.2 type and in hemiarthroplasty group thirteen fractures were A2.2 and rests were A2.3 in both groups. The average blood loss for TFN and hemiarthroplasty was 132.5 millilitres and 300 millilitres respectively. Full weight bearing was achieved in TFN and hemiarthroplasty group after $49.33 \pm 5.47$ days and $5.8 \pm 1.45$ days respectively. Functional results using Harris hip score at three months, six months, and one year are better in hemiarthroplasty group but almost similar at one and half year.

Conclusion: Primary hemiarthroplasty provides a stable pain free mobile joint and is a better modality of treatment in osteoporotic elderly people who sustained unstable intertrochanteric fractures. It definitely reduces morbidity. However overall long term functional outcomes are almost similar for two groups.
\end{abstract}

Key Words: Fractures, intertrochanteric, hemiarthroplasty, internal fixation

\section{Introduction}

Unstable osteoporotic intertrochanteric neck femur fractures of elderly patients are associated with high rates of morbidity and mortality due to the need for prolonged immobilization, although results are improved with use of recent modalities of internal fixation. ${ }^{1}$

In these patients due to combination of osteoporosis and instability, early resumption to full weight bearing is difficult. Because of prolonged immobilization, complications like deep vein thrombosis, hypostatic pneumonia, pressure sores, dehydration, atelectasis, metabolic disturbances, etc are likely. So they have increased the morbidity and mortality threshold. The comminuted intertrochanteric fractures being in cancellous area, fixation of all fragments is difficult. The posteromedial void is generally present which makes the fracture very unstable. ${ }^{2}$

Recently popular modality is 4 th generation of intramedullary nails like the proximal femoral nails. ${ }^{3}$ But these are not found to be very suitable in Indian population because of variation in anthropometry of proximal femur. This may lead to an increased difficulty in placement of femoral neck screws. Therefore, Trochanteric Fixation Nail (TFN) which is smaller in size than Proximal Femoral Nail (PFN) was introduced and has been found suitable for Indian population. ${ }^{4}$ But even with these implants immobilization is required for few days.

Management of such cases with primary hemiarthroplasty permits early mobilization, thus avoiding most of the complications of recumbence. ${ }^{5}$ The patient is mobilized early giving good rehabilitation and better options for dependence free living.

There is extensive literature published on results obtained with both modalities of treatment. However, there are relatively few studies which have compared the results of both methods. So we have hereby tried to compare between two methods in terms of results obtained. 


\section{Material \& Methods}

This study comprises a series of unstable osteoporotic intertrochanteric neck femur fractures treated by either Trochanteric Fixation Nail (TFN) or cemented bipolar hemiarthroplasty at our institute. Thirty patients were treated with TFN and thirty with cemented bipolar hemiarthroplasty. Patients aged above 65 years having unstable osteoporotic intertrochanteric neck femur fractures who are willing to participate in study were included in the study. Based on admission at hospital alternate patient was assigned to either group.

A thorough clinical examination was done. Associated co-morbidities were noted. AO/ASIF classification (A1-A3) was used to classify the fractures.

The prostheses used in this study are:-

Trochanteric fixation nail (TFN):-

TFN is made of a stainless steel 316L type. The system consists of a cannulated nail, cannulated hip screws 8 millimeters and 6.4 millimeters, locking bolts ( 4.9 millimeters). The proximal diameter of the nail is 15 millimeters and length is 180 millimeters. The diameter varies from 9 to 12 millimeters. The angle between the nail and screw used is either $130^{\circ}$ and $135^{\circ}$. Distally there are two holes for static and dynamic locking.

\section{Bipolar prosthesis:-}

The Bipolar prosthesis consists of femoral stem and head. Cement is used for fixation of the stem. Head consists of one inner bearing of metal on polyethylene interface metal polyethylene cup.

Opervative protocol:-

All patients were operated under regional anesthesia.

\section{Surgical Procedures:-}

Trochanteric Fixation Nail (TFN):-

Closed reduction was achieved after positioning on fracture table. Incision was made just proximal to the tip of greater trochanter parallel to the femoral shaft.

Entry was made with a curved awl just lateral to the tip of greater trochanter. A guide wire was passed through the entry point across the fracture site. Gradual reaming was done according to the canal diameter. Entry point was reamed with entry reamer. The nail of size less than 1 millimeters of largest reamer was inserted over guidewire. Proximal and distal locking was done. The wound was closed in layers.

\section{Cemented Bipolar Hemiarthroplasty:-}

All patients were operated in lateral position. The posterolateral approach was used as it gives adequate exposure with minimal bleeding. After removing head, size of head was measured. Femoral canal was prepared using reamers. Entry point was made as lateral as possible in line with the inner wall of the lateral cortex. Whenever posteromedial comminution was found, it was reconstructed with Kirschners wires and stainless steel wires. Femoral canal cleaned with normal saline and dried with roller gauze. Cement is then pushed into the femoral canal with a cement introducer and to prevent sinking of cement distally in canal, a cement restrictor was used. After the initial setting of the cement, implant of appropriate size was inserted after ascertaining the correct degree of anteversion and length. Joint was relocated with gentle traction to limb with thumb pressure and external rotation. Joint movements and stability was checked. Wounds were closed over negative suction drain.

\section{Post operative protocol}

Trochanteric Fixation Nail (TFN):-

Postoperatively active quadriceps exercises, ankle and toe movements and knee mobilizing exercises begun from second day. Toe touch weight bearing started with walker on second day followed by partial weight bearing till radiological union seen on X- ray followed by full weight bearing thereafter. Sutures were removed between 12-14 days.

Bipolar Hemiarthroplasty: - DVT prophylaxis was given if patient was at high risk. Static exercise in bed for glutei, hamstrings and quadriceps and breathing exercises were started on first post operative day. Drains were removed after 48 hours. Full weight bearing was allowed from third day. Sutures were removed between 12-14 days.

Patients were followed at three months, six months, one year and one and half year. Functional assessment of patients was done using Harris Hip Scoring system; formulated by W.H Harris as described in Table no.1. ${ }^{4}$ 


\section{Observations And Results}

In our study we derived the following results:-

Average age of patients in TFN group was $75.73 \pm 6.57$ years and in hemiarthroplasty group was 78.07 \pm 6.16 years. There were eighteen male patients in TFN group and seventeen in hemiarthroplasty group, rest were females. The youngest patient in our series was 67 years and the oldest was 92 years. In TFN group in seventeen and in hemiarthroplasty group in twelve fractures involved right side. Rest fractures were left sided. Average trauma surgery interval for TFN group was 5.7 days (range 2 to 12 days) and for hemiarthroplasty group was 6.56 days (range 2 to 12 days). The average surgery time for TFN was 74.33 minutes (range 55 to 95 $\mathrm{min}$ ), and for hemiarthroplasty was 86.33 minutes (range 65 to $115 \mathrm{~min}$ ). Average hospital stay for TFN group was 18.23 days (range 14 to 24 days) and for hemiarthroplasty was 18.77 days (range 14 to 26 days). In TFN group fourteen fractures were A2.2 type and in hemiarthroplasty group thirteen fractures were A2.2 and rest were A2.3. Out of sixty patients, twenty two patients were suffering from hypertension with ischaemic heart disease, eleven patients were suffering from diabetes mellitus, eight patients were suffering from both hypertension and diabetes mellitus, five patients had cataract and four patients had chronic obstructive pulmonary disease (COPD). Fifty five patients were community ambulatory and five were household ambulatory. The average blood loss for TFN was 132.5 milliliters (range 50 to 350 milliliters), and for hemiarthroplasty was 300 milliliters (range 150 to 550 milliliters). The p-value was more than 0.05 , indicating that average blood loss for hemiarthroplasty was significantly more than Trochanteric Fixation Nailing. Full weight bearing was achieved in TFN group after $49.33 \pm 5.47$ days (41 to 57 days) and in hemiarthroplasty group after $5.8 \pm 1.45$ (4 to 9 days). The difference was found statistically significant ( $p>0.05$ ), indicating that there was significant statistical difference between time to achieve full weight bearing.

In our series most of the complications were minor and resolved with minimal interventions without causing any lasting morbidity. Complications are depicted in table no. 2.

Six patients expired during follow up. Out of six there was one hospital death of a patient from hemiarthroplasty group who expired on third post operative day. So the final functional assessment of 54 patients was done at the last follow-up at one and half years. Functional results using Harris hip score at three months, six months, one year and at one and half year are depicted in table no 3,4, 5 and 6 respectively.

\section{Discussion}

Outcome of treatment of intertrochanteric fractures depends on quality of bone, age of patient, general health, trauma surgery interval, adequacy of treatment, co-morbidities and stability of fixation. ${ }^{6,7,8}$

Intertrochanteric fractures in the elderly pose certain special problems. In this age group the fracture configuration is generally comminuted with presence of extensive osteoporosis. There is problem with correct and accurate placement of the implant and hold of the implant hence prolonged immobilization is required to achieve complete union. On the other hand there is a need for rapid full weight bearing mobilization of this group of patients as they are generally medically compromised due to age and associated diseases. In addition, these patients may not have adequate psychomotor skills required for graded and protected weight bearing required with internal fixation. Hence there are two conflicting requirements that need to be addressed to in a balanced way. So despite the publication of reports of randomized trials and comparative studies ${ }^{6,9,10}$ treatment of unstable intertrochanteric fractures in elderly patients is still controversial. Literature concerning the treatment and results of unstable osteoporotic intertrochanteric fracture of the hip is extensive. Holi Dimon and Hughston, Sarmeinto and Willams have done outstanding work in attempt to change an unstable intertrochanteric fracture into a stable one and fix it with a device until it heals. The reported complication rate for treating unstable intertrochanteric fracture range from $18-50 \% .^{11,12}$

Elderly patients even if they are in good health cannot usually be mobilized without some weight bearing on the involved limb. This has led to periodic introduction of various designs and stable implants. TFN is one such design introduced considering anthropometry of Indian population. It acts as a buttress to prevent medialisation of the shaft and provides more efficient load transfer. ${ }^{13}$ It is designed to provide linear intraoperative compression of head neck segment to shaft along with rotational stability which minimizes neck malunions resulting in negligible complication rate. ${ }^{14}$ It also reduces stress concentration at the tip and the smaller distal diameter may prevent femoral shaft fractures. ${ }^{15}$ It has been proved to be a superior implant compared to previous implants for stable and unstable intertrochanteric fractures in terms of operating time, surgical exposure, blood loss, and complication rates. ${ }^{16}$

So we can summarize problems associated with unstable fractures in the geriatric age group as:

$>$ Osteoporosis.

$>$ Comminution.

$>\quad$ Age related medical illnesses.

$>\quad$ Need for rapid mobilization. 
Inability to do partial and graduated weight bearing.

So the surgeon is often confronted with a challenge and dilemma between achieving bony union in a weakened bone stock, against need for early mobilization. All these problems are addressed by hemiarthroplasty. So some surgeons have recommended prosthetic replacement for the treatment of unstable osteoporotic intertrochanteric fractures. ${ }^{17}$

Largest series available in literature comparing both methods is study done by Peifu Tang et al ${ }^{18}$ with 303 cases. He reported complications which include infection, non union, screw breakage, dislocations and screw cut outs. Other studies include studies done by Jun Shen et al ${ }^{19}$ and Kim et al ${ }^{17}$ with 124 and 58 patients respectively.

In our study, we selected equal numbers of patients for both surgical groups. We tried minimizing trauma surgery interval. Partial weight bearing could be achieved earlier in hemiarthroplasty group as compared to Trochanteric Fixation Nail group. So is full weight bearing which we could achieve earlier in hemiarthroplasty patients. This lead to decreased incidence of pressure sores, respiratory complications etc in these patients decreasing morbidity.

There was one case of screw cut out in TFN group which had to be revised with total hip replacement. There was one case of varus collapse. Three patients developed pressure sores and two patients suffered pneumonia which required medical management. On the other hand no such complications seen in hemiarthroplasty group. Only one patient developed deep venous thrombosis (DVT) as prophylaxis was given to all high risk patients. No revisions were required. But there were four deaths in hemiarthroplasty group as against two deaths of TFN group.

In our series the functional outcomes in terms of Harris Hip Score were better in hemiarthroplasty group than TFN group in initial follow ups. But at final follow up at the end of one and half year scores were almost similar in both groups. Although with primary hemiarthroplasty overall mortality may not be reduced, but there is definite reduction in the morbidity.

\section{Conclusion}

Primary hemiarthroplasty provides a relatively stable pain free mobile joint and is a better modality of treatment in osteoporotic elderly people who sustained unstable intertrochanteric fractures. Early mobilization is possible as the technique bypasses of fracture healing and provides immediate stability and mobility thereby avoiding the problems of recumbence. However long term functional outcomes are almost similar for two groups.

\section{Acknowledgement}

Authors acknowledge the immense help received from scholars whose articles are cited and included in references of this manuscript. The authors are also grateful to authors/editors/publishers of all those articles, journals, books from where the literature for this article has been reviewed and discussed.

\section{References}

[1]. Campbell's operative orthopedics; Philadelphia: Mosby Elsevier; 2008.Vol 3; 11th edition: 3239-3256.

[2]. Grisso JA, Kelsey JI, Strom BL, and Chio GY. Risk factors for falls as a cause of hip fractures in women. New England journal of medicine. 1991;324:1326-1331.

[3]. Meislin RJ, Zuckerman JD, Kummer FJ, et al. A biomechanical evaluation of the gamma nail. J Bone Joint Surg.1998; 70-A:239.

[4]. Anchal Kumar. Femoral neck geometry and rationale of placement of the proximal femoral nail and its relation with fracture risk in the Indian population review of 120 cases. 2010: Gulmohar Hospital, Ranchi.

[5]. Sturt green. Bipolar prosthetic replacement for the management of unstable intertrochanteric fractures in the elderly. Clin Orthop Relat Res. 1987;224:169-177.

[6]. Kyle RF, Gustilo RB, Premer PF. Analysis of Six hundred and Twenty-two intertrochanteric Hip Fractures. J. Bone Joint Surg. 1979 March; 61-A: 216-21.

[7]. Dahl E. Mortality and life expectancy after hip fractures. Acta Orthop Scand. 1980 Feb; 51(1)163-70.

[8]. Kaufer H. Mechanics of the treatment of hip injuries. Clin Orthop Relat Res. 1980 Jan-Feb;146:53-61.

[9]. Cleas H, Broos P, Stappaerts K. Pertrochanteric Fractures in Elderly patient Treatment with Ender's nail, blade-plate or endoprosthesis? Injury. 1985;16(4):261-64.

[10]. Heyse-Moore G.H, MacEachen AC, and Jameson Evans DC. Treatment of trochanteric fractures of the femur. J Bone Joint Surg. 1983;65-B: 262-267.

[11]. Sarmeinto. Intertrochanteric fractures of femur 150-degree angle nail plate fixation and early rehabilitation, a preliminary report of 100 cases. J Bone Joint Surgery.1963 June;45-A:706-722.

[12]. Dimon JH, Hughston JC. Unstable intertrochanteric fractures of hip. J Bone Joint Sug.1967;49-A:440-450.

[13]. Morihara T, Arai Y,Tokugawa S, Fujita S, Chatani K, Kubo T. Proximal femoral nail for treatment of trochanteric femoral fractures. Journal of Orthopaedic Surgery 2007;15(3):273-7.

[14]. Ruecker AH, Rupprecht M, Gruber M, Gebauer M, Barvencik F, Briem D, Rueger JM: The treatment of intertrochanteric fractures: results using an intramedullary nail with integrated cephalocervical screws and linear compression. J Orthop Trauma. 2009;23(1):22-30

[15]. Bienkowski P, Reindl R, Berry GK, Iakoub E, Harvey EJ: A new intramedullary nail device for the treatment of intertrochanteric hip fractures: Perioperative experience. J Trauma. 2006;61(6):1458-62. 
[16]. Gill JB, Jensen L, Chin PC, Rafiei P, Reddy K, Schutt RC Jr : Intertrochanteric hip fractures treated with the trochanteric fixation nail and sliding hip screw. J Surg Orthop Adv. 2007;16(2):62-6.

[17]. Kim SY, Kim YG, Hwang JK. Hemiarthroplasty compared with intramedullary fixation of unstable intertrochanteric fractures: J Bone Joint Surg. 2005 Oct;87-A: 2186-92.

[18]. Peifu Tang et al. Proximal femoral nail antirotation versus hemiarthroplasty: A study for treatment of intertrochanteric fractures. Injury. 2012 Oct;43(6) : 876-881.

[19]. Jun Shen et al. Bipolar hemiarthroplasty compared with internal fixation for unstable intertrochanteric fractures in elderly patients. J Orthop Science.2012 Nov;17(6):722-9.

\section{Tables}

Table NO. 1:- Harris Hip Scoring For Functional Evaluation of Hip

Point scale with maximum of 100 points distributed as follows:-

Pain 44

Function $\quad 47$

Range of motion $\quad 05$

Absence of deformity 04

Total

100

\begin{tabular}{|c|c|c|}
\hline I & PAIN & 44 \\
\hline 1 & Totally disabled, crippled, pain in bed, bedridden & 00 \\
\hline 2 & Marked pain, serious limitation of activities & 10 \\
\hline 3 & Moderate plain, tolerable but makes concession to plain & 20 \\
\hline 4 & Mild pain, no effect on average activities & 30 \\
\hline 5 & Slight, occasional, no compromise in activity & 40 \\
\hline \multirow[t]{2}{*}{6} & None, or ignores it & 44 \\
\hline & Total & \\
\hline II & Function & 47 \\
\hline A & Distance walked & \\
\hline 1 & Bed and chair only & 00 \\
\hline 2 & Two or three blocks & 05 \\
\hline 3 & Six blocks & 08 \\
\hline 4 & Unlimited & 11 \\
\hline \multirow[t]{2}{*}{$\mathrm{B}$} & Activities & \\
\hline & Shoes \& Socks & \\
\hline 1 & Unable to fit or tie & 00 \\
\hline 2 & With difficulty & 02 \\
\hline \multirow[t]{2}{*}{3} & With ease & 04 \\
\hline & Public transportation & \\
\hline 1 & Unable to use public transportation (bus) & 00 \\
\hline \multirow[t]{2}{*}{2} & Able to use transportation (bus) & 01 \\
\hline & Limp & \\
\hline 1 & Severe or unable to walk & 00 \\
\hline 2 & Moderate & 05 \\
\hline 3 & Slight & 08 \\
\hline \multirow[t]{2}{*}{4} & None & 11 \\
\hline & Support & \\
\hline 1 & Two crutches or not able to walk & 00 \\
\hline 2 & Two canes & 02 \\
\hline 3 & One crutch & 03 \\
\hline 4 & Cane most of the time & 05 \\
\hline 5 & Cane for long walks & 07 \\
\hline \multirow[t]{2}{*}{6} & None & 11 \\
\hline & Stairs & \\
\hline 1 & Unable to do stairs & 00 \\
\hline 2 & In any manner & 01 \\
\hline 3 & Normally using a railing & 02 \\
\hline \multirow[t]{2}{*}{4} & Normally without using a railing & 04 \\
\hline & Sitting & \\
\hline 1 & Unable to sit in any chair comfortably & 00 \\
\hline 2 & On a high chair for $30 \mathrm{~min}$ & 03 \\
\hline \multirow[t]{2}{*}{3} & Comfortably on a ordinary chair for one hour & 05 \\
\hline & Total & \\
\hline III & $\begin{array}{l}\text { Motions } \\
\text { Flexion+ Abduction + Adduction + External rotation }+ \text { internal } \\
\text { rotation= }\end{array}$ & 05 \\
\hline 1 & 00 to $29^{\circ}$ & 00 \\
\hline 2 & 30 to $59^{\circ}$ & 01 \\
\hline 3 & 60 to $99^{\circ}$ & 02 \\
\hline 4 & 100 to $159^{\circ}$ & 03 \\
\hline
\end{tabular}




\begin{tabular}{|l|l|l|}
\hline 5 & 160 to $209^{\circ}$ & 04 \\
\hline 6 & 210 to $300^{\circ}$ & 05 \\
\hline & Total & \\
\hline & & 04 \\
\hline IV & Deformity & 00 \\
\hline 1 & Flexion deformity $30^{\circ}$ of more & 01 \\
\hline 2 & Flexion deformity less than $30^{\circ}$ & \\
\hline & & 00 \\
\hline 1 & Fixed adduction $10^{\circ}$ more & 01 \\
\hline 2 & Fixed adduction less than $10^{\circ}$ & 00 \\
\hline 1 & Fixed internal rotation(in extension) $10^{\circ}$ or more & 0 \\
\hline 2 & Fixed internal rotation(inextension) less than $10^{\circ}$ & 00 \\
\hline 1 & Limb length discrepancy more than or equal to $3.2 \mathrm{cms}$ & 01 \\
\hline 2 & Limb length discrepancy less than 3.2cms & \\
\hline & Total & 100 \\
\hline & Total of I+II+III+IV & \\
\hline
\end{tabular}

The score is reported as follows:-

HHS between 90 to 100- Excellent results

HHS between 80 to 89 - Good

HHS between 70 to 79 - Fair

HHS between 60 to 69-Poor, and

HHS below 60:- as a failed result.

* HHS: - Harris Hip Score

Table 2:- Complications in Two Groups

\begin{tabular}{|l|l|l|}
\hline Complications & TFN & $\begin{array}{l}\text { Bipolar } \\
\text { Hemiarthroplasty }\end{array}$ \\
\hline & & \\
Sciatic nerve palsy & 0 & 0 \\
Pressure sores & 3 & 0 \\
Pneumonia & 2 & 0 \\
Sup infection & 1 & 2 \\
Deep infection & 0 & 1 \\
Cutting out of screws & 1 & - \\
Shortening & 0 & 2 \\
Dislocation & - & 0 \\
Death & 2 & 4 \\
Periprosthetic fracture & 0 & 0 \\
Protrusion Acetabuli & - & 0 \\
Varus collapse & 1 & - \\
Revision Surgery & 1 & 0 \\
Deep venous Thrombosis & 0 & \\
& & \\
\hline
\end{tabular}

Table 3:- Functional Results at 3 Months

\begin{tabular}{|l|l|l|}
\hline Results & TFN & $\begin{array}{l}\text { Bipolar } \\
\text { Hemiarthroplasty }\end{array}$ \\
\hline Excellent (HHS 90-100) & 2 & 9 \\
Good (HHS 80-89) & 15 & 11 \\
Fair (HHS 70-79) & 11 & 8 \\
Poor (HHS 60-69) & 2 & 1 \\
Failed (HHS below 60) & 0 & 0 \\
\hline
\end{tabular}

* HHS: - Harris Hip Score

Table 4:- Functional Results at 6 Months

\begin{tabular}{|l|l|l|}
\hline Results & TFN & $\begin{array}{l}\text { Bipolar } \\
\text { Hemiarthroplasty }\end{array}$ \\
\hline Excellent (HHS 90-100) & 9 & 14 \\
Good (HHS 80-89) & 12 & 9 \\
Fair (HHS 70-79) & 6 & 4 \\
Poor (HHS 60-69) & 2 & 1 \\
Failed (HHS below 60) & 0 & 0 \\
\hline
\end{tabular}

* HHS: - Harris Hip Score 
Table 5:- Functional Results at 1 Year

\begin{tabular}{|l|l|l|}
\hline Results & TFN & $\begin{array}{l}\text { Bipolar } \\
\text { Hemiarthroplasty }\end{array}$ \\
\hline Excellent (HHS 90-100) & 13 & 16 \\
Good (HHS 80-89) & 9 & 9 \\
Fair (HHS 70-79) & 4 & 2 \\
Poor (HHS 60-69) & 2 & 1 \\
Failed (HHS below 60) & 0 & 0 \\
\hline
\end{tabular}

* HHS: - Harris Hip Score

Table 6:- Functional Results at 1 and $1 / 2$ Years

\begin{tabular}{|l|l|l|}
\hline Results & TFN & $\begin{array}{l}\text { Bipolar } \\
\text { Hemiarthroplasty }\end{array}$ \\
\hline Excellent (HHS 90-100) & 16 & 17 \\
Good (HHS 80-89) & 9 & 8 \\
Fair (HHS 70-79) & 2 & 1 \\
Poor (HHS 60-69) & 1 & 0 \\
Failed (HHS below 60) & 0 & 0 \\
\hline
\end{tabular}

* HHS: - Harris Hip Score

Figures

I Trochanteric Femoral Nailing

Case no.1:- a) Pre operative $X$ ray

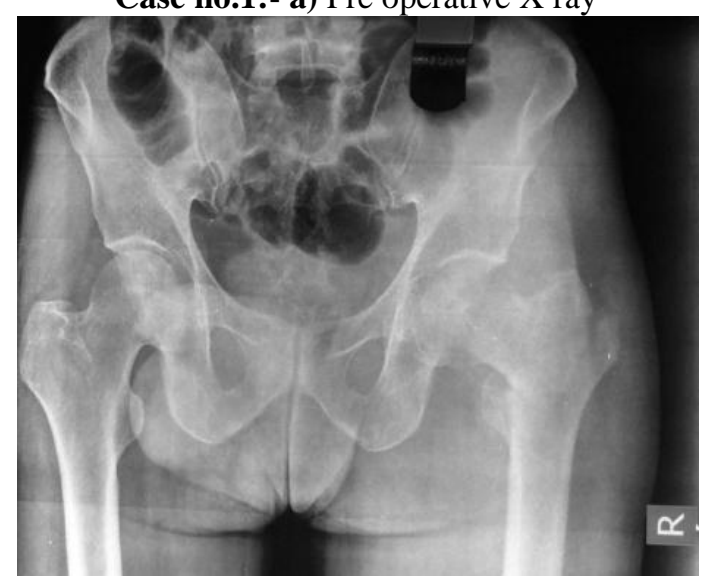

b) Post operative $X$ ray 


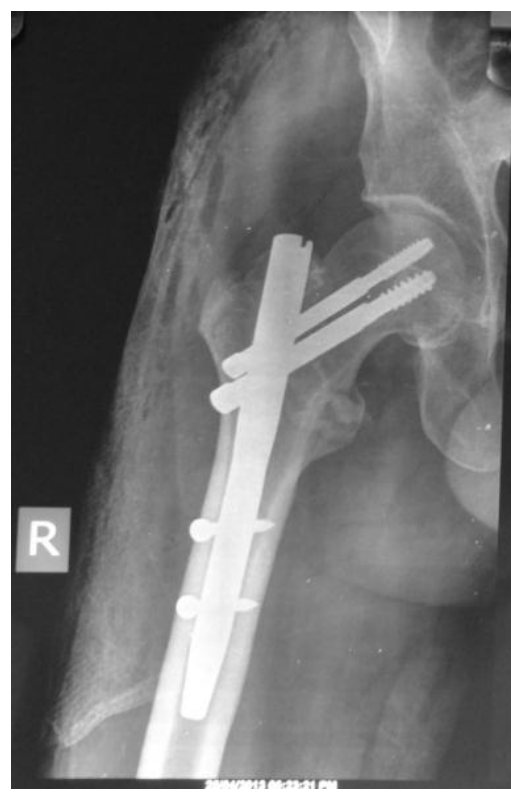

Case no. 2:- a) Pre operative $X$ ray

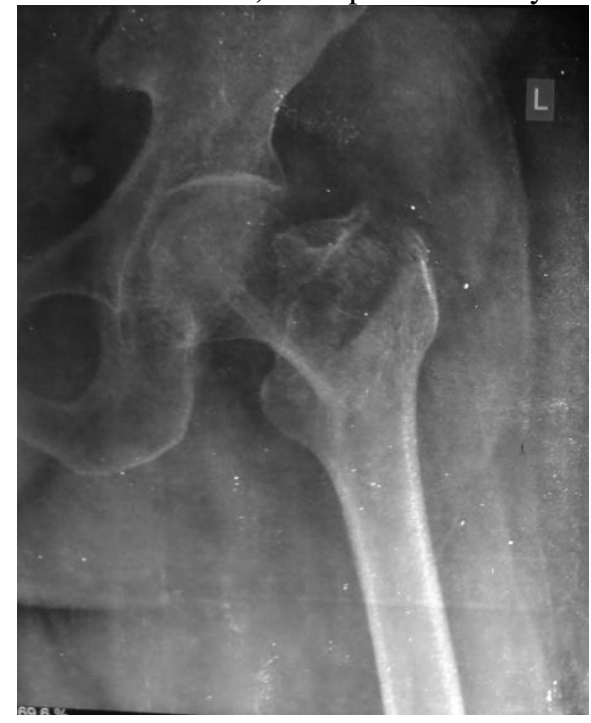

b) Post operative $\mathrm{X}$ ray 


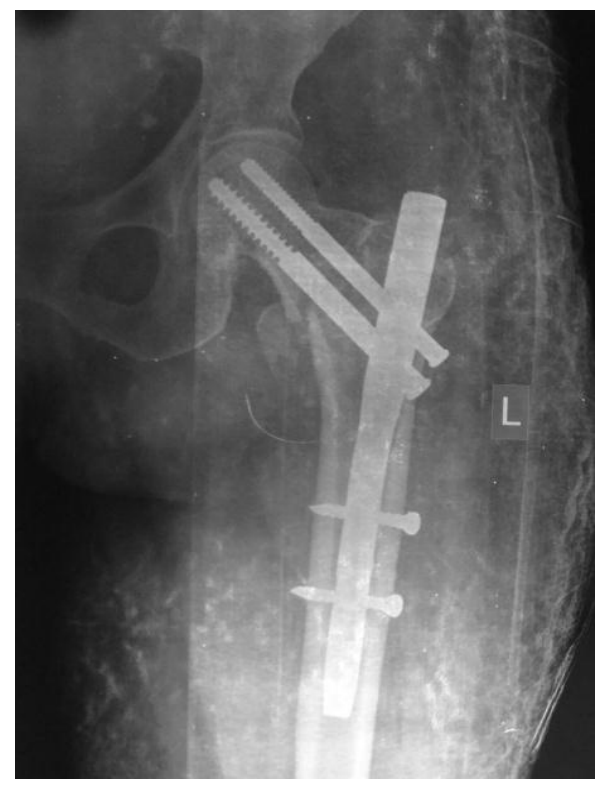

\section{Cemented Bipolar Hemiarthroplasty}

Case 1:- a) Pre operative $X$ ray

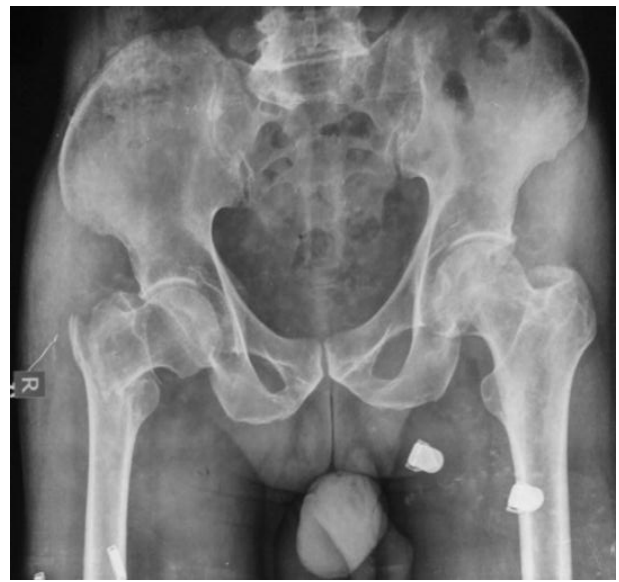

b) Post operative $\mathrm{X}$ ray

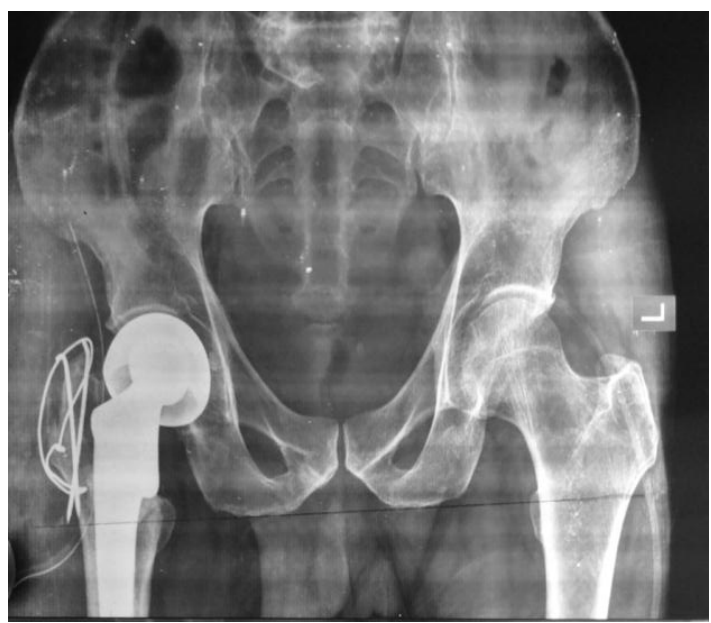

Case 2:- a) Pre operative Xray 


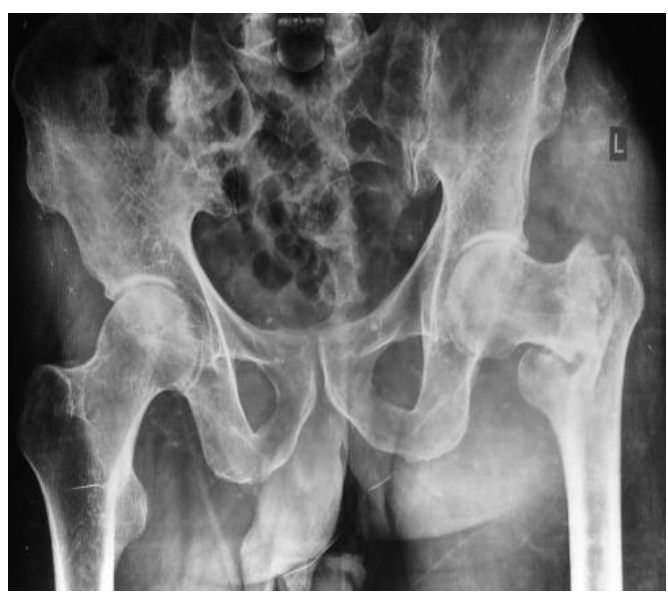

b) Post operative $\mathrm{X}$ ray

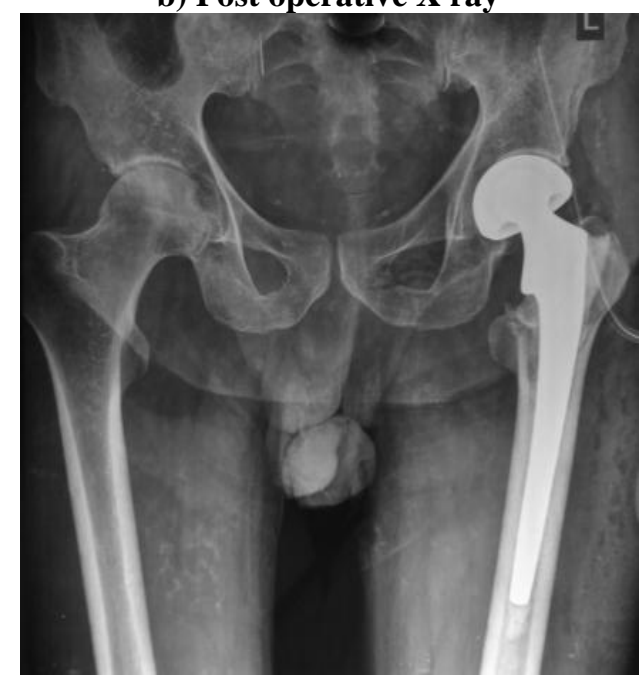

